\title{
Soil Moisture Remote Sensing across Scales
}

\author{
Nemesio Rodríguez-Fernández ${ }^{1, *}$, Ahmad Al Bitar ${ }^{1}$,, Andreas Colliander ${ }^{2}$ and Tianjie Zhao ${ }^{3}$ \\ 1 Centre d'Etudes Spatiales de la Biosphère (CESBIO), Université de Toulouse, Centre National d'Etudes \\ Spatiales (CNES), Centre National de la Recherche Scientifique (CNRS), Institut de Recherche pour le \\ Dévelopement (IRD), Université Paul Sabatier, 18 av. Edouard Belin, bpi 2801, 31401 Toulouse, France; \\ ahmad.albitar@cesbio.cnes.fr \\ 2 Jet Propulsion Laboratory, California Institute of Technology, Pasadena, CA 91125, USA; \\ andreas.colliander@jpl.nasa.gov \\ 3 Institute of Remote Sensing and Digital Earth, Chinese Academy of Sciences, Beijing 100101, China; \\ zhaotj@radi.ac.cn \\ * Correspondence: nemesio.rodriguez@cesbio.cnes.fr; Tel.: +33-(0)561-55-8577
}

Received: 11 January 2019; Accepted: 16 January 2019; Published: 19 January 2019

\begin{abstract}
Soil moisture plays an important role in the water, carbon, and energy cycles. We summarize the 13 articles collected in this Special Issue on soil moisture remote sensing across scales in terms of the spatial, temporal, and frequency scales studied. We also review these papers regarding the data, the methods, and the different applications discussed.
\end{abstract}

Keywords: soil moisture; L-band; passive radiometry; synthetic aperture radar; GNNS

\section{Introduction}

Soil moisture plays an important role in the water, carbon, and energy cycles. The amount of moisture in the soil is an important variable to understand the coupling of the surface and the atmosphere. It is a key component in improving weather forecasting and climate models, and it has been recognized as an essential climate variable. Assimilation of soil moisture to land surface models has resulted in increased understanding of processes controlling the energy exchange at the land-atmosphere interface. It is also used to improve rainfall estimations, drought monitoring, land slide prediction, and flood forecasting. Thanks to a number of sensors with different characteristics, it is possible to study the soil moisture content at different spatial scales from tens of kilometers (Advanced Scatterometer (ASCAT), Soil Moisture Active Passive (SMAP), Soil Moisture and Ocean Salinity (SMOS), Advanced Microwave Scanning Radiometer 2 (AMSR-2), Microwave Radiation Imager (MWRI) on board the FengYun-3 satellites, etc.) to tens/hundreds of meters (Sentinel-1, Radarsat-2, GF-3, etc.), or even at sub-meter resolution using drones. By combining data from different instruments with sensors across the electromagnetic spectrum (different microwave bands, visible, infra-red, active, and passive), it is possible to improve the quality of the soil moisture retrievals obtained with a single instrument. Using the currently-available satellites, soil moisture can be monitored at daily frequency and disseminated in near-real time. Finally, a harmonized processing of observations from different sensors can provide long-term soil moisture records for climate studies.

This wealth of sensors and new results on soil moisture remote sensing justify a new Special Issue following the previous Special Issue "Retrieval, Validation and Application of Satellite Soil Moisture Data" (available online: https://www.mdpi.com/journal/remotesensing/special_issues/soilmoisture (accessed on 7 December 2018)). In the current Special Issue, we welcomed studies on remote sensing of soil moisture across different spatial and temporal scales. The potential topics for these included the retrieval approaches of soil moisture, the validation of soil moisture retrievals, and the use of 
remotely-sensed soil moisture data for scientific research or operational applications. The specific areas of interest included:

- Retrieval algorithms, in particular using multi-wavelength, active and passive data, both based on physical models and data-driven methods

- Downscaling satellite soil moisture, merging data from sensors with different spatial resolutions

- Approaches for the harmonized processing of data coming from different sensors to construct longer, coherent, soil moisture records

- Validation of satellite soil moisture products, in particular using new techniques for up-scaling and new measurements.

- Applications of remotely-sensed soil moisture data including data assimilation and disaster assessment

- $\quad$ Studies addressing new remote sensing missions

Most of these aspects were covered in the Special Issue, as discussed in the next section.

\section{Overview of the Papers}

A total number of 34 manuscripts was received for this Special Issue. Among them, thirteen manuscripts were accepted for publication after revision by three or more external reviewers. Below, we briefly review the published papers.

\subsection{Remotely-Sensed Soil Moisture Evaluation}

The evaluation and validation of remote sensing measurements is a subject of prime importance. In line with the previous Remote Sensing Special Issue on Soil Moisture Validation, the current Special Issue contains a few studies dealing with remote sensing soil moisture validation, which offer new insights into soil moisture validation. Cui et al. [1] presented an evaluation using in situ measurements from the Little Washita Watershed network in the United States and the REMEDHUSnetwork in Spain. Both networks are frequently used for remote sensing validation, and they are particularly interesting because they have many sensors within a satellite footprint for $\sim 40-\mathrm{km}$ resolution instruments. However, the particularity of the study of Cui et al. [1] is that it was done simultaneously for SMAP, SMOS, MWRI/FY-3B, AMSR-2 (using two different algorithms), and ESA soil moisture CCI datasets. As usual, the results depend on the quality metrics and differ for the two networks; all datasets but AMSR2 LPRM show the best results for at least one network and one quality metric.

$\mathrm{Li}$ et al. [2] presented an evaluation of the SMAP Level 3 original (36- $\mathrm{km}$ sampling) and enhanced (9-km sampling) soil moisture datasets against model simulations (10-km resolution) and in situ measurements over the Tibetan Plateau. They verified the similar performances for the two SMAP products in spite of the different sampling grids.

Moving towards even smaller spatial scales, El Hajj et al. [3] discussed the evaluation of Sentinel 1 and Sentinel 2 soil moisture retrievals over the southwest of France (using the SMOSMANIAnetwork) at 1-, 9-, and 25-km resolutions. They also evaluated different SMAP products, including the SMAP/Sentinel-1 1-km product and several SMOS and ASCAT products. Once again, the best results depended on the quality metrics, but it is interesting that in some regions, the standard deviation (or unbiased-root mean square) of the difference was $0.06-0.07 \mathrm{~m}^{3} \mathrm{~m}^{-3}$, significantly larger than the target of $0.04 \mathrm{~m}^{3} \mathrm{~m}^{-3}$ [4]. However, the spatial representation uncertainty between the in situ measurements and the area-averaging satellite observations was not quantified in the investigation and could be the major source of differences. It is also noteworthy that, for the time being, the high resolution products do not show a clear quality improvement with respect to coarse-scale products when compared to single-point in situ measurements.

\subsection{Applications for Drought Assessment and Rainfall and Evaporation Estimation}

Two applications in Brazil are discussed in this Special Issue. Souza et al. [5] discussed the evaluation of SMOS soil moisture data in the state of Pernambuco in Brazil, including in situ sensors, 
both in forest and arid regions; showing a net decrease of performances from arid to forest regions. They also showed that the use of SMOS data provides additional information to precipitation data that allows the monitoring of drought periods.

Paredes-Trejo et al. [6] showed that the SM2RAINmethod using ESA Climate Change Initiative soil moisture as input exhibits good performances in estimating rainfall from soil moisture in northeastern Brazil, except under very dry or very wet conditions.

Finally, Small et al. [7] described an approach to estimate direct evaporation from soil by combining soil drying rates computed from SMAP soil moisture with model calculations of the vertical fluxes.

\subsection{Retrieval Approaches}

A semi-empirical Signal-to-Noise Ratio (SNR) model was proposed by Han et al. [8] to estimate soil moisture using the Global Navigation Satellite System-Interferometry and Reflectometry technique. In addition, a more physical-based soil moisture retrieval algorithm using passive radiometers was presented by Schwank et al. [9], who discussed an alternative to the well-known "Tau-Omega" approach. They showed that models dealing with more complex physical phenomena, such as multiple scattering and reflections, can provide better retrievals for dense (and strongly-scattering) vegetation while giving the same results as the "Tau-Omega" model for sparse and low vegetation. Furthermore, using a passive radiometer over wheat and mustard fields, Meyer et al. [10] showed the importance of using a time-, polarization-, and angle-dependent optical depth $(\tau)$ parameter at the field scale for accurate soil moisture retrieval. Although the importance of those parameters is probably less important at a large scale, these effects should probably be taken into account for multi-incidence angle radiometers such as the SMOS follow-on, SMOS-HR (with an increased resolution of $10 \mathrm{~km}$ [11]).

\subsection{Data Fusion and Long Time Series}

Extracting synergies from multi-source data bases is one of the strengths of machine learning techniques. In this issue, $\mathrm{Xu}$ et al. [12] showed a new approach starting from SMAP soil moisture data and using land cover, surface soil temperature, and vegetation water content from NDVI. They showed that this technique can be used to improve SMAP retrievals after training a neural network using in situ measurements as the target.

Lorenz et al. [13] also discussed a statistical technique for SMAP enhanced (9-km sampling) and SMOS data fusion to increase the length of a consistent SMAP/SMOS soil moisture time series. The Copula-combined SMOS-SMAP (CoSMOP) brightness temperatures are statistically consistent with SMAP brightness temperatures, and the soil moisture retrieved from CoSMOP reduces the average RMSE of the original SMOS data by 15\% over Soil Climate Analysis Network (SCAN) sites.

\subsection{On the Interest of New Observing Systems}

Cenci et al. [14] compared a SAR in geostationary orbit to a more traditional SAR in polar orbit, in terms of spatial and temporal resolution, by means of data assimilation into hydrological models. They found that a geostationary SAR can be a valuable contribution to hydrological applications if the spatial resolution is kept high $(\sim 100 \mathrm{~m})$.

\subsection{Data Assimilation for Carbon-Cycle Monitoring}

Wu et al. [15] discussed the importance of estimating reliably-modeled $\mathrm{CO}_{2}$ fluxes between the terrestrial biosphere and the atmosphere to constrain the carbon cycle and policy strategies limiting anthropogenic carbon emissions. They showed that SMOS L3 soil moisture and FAPAR (Fraction of Absorbed Photosynthetically-Active Radiation) can be used to improve model predictions with the terrestrial biosphere model, BETHY (Biosphere, Energy Transfer and Hydrology), using data assimilation. When the optimized parameter set derived from multi-site assimilation with soil 
moisture and FAPAR is applied to global-scale simulations, it improves the model-data fit against atmospheric $\mathrm{CO}_{2}$.

\section{Conclusions}

We are living in a kind of "golden age" of soil moisture research with a number of complementary sensors in terms of frequency bands, observing techniques, and spacial resolutions (SMAP, SMOS, FY3B, Aquarius, AMSR-2, ASCAT, Sentinel 1, etc.). Continuity for ASCAT and AMSR is foreseen, for instance MetOp-C has been recently launched carrying a new ASCAT instrument. In contrast, the long-term continuity of passive microwave L-band observations could be compromised in the future. Therefore, it is recommended to start activities defining a future L-band observation system based on the lessons learned from SMOS and SMAP [4,16,17]. The Copernicus Imaging Microwave Radiometer (CIMR) project could carry an L-band radiometer. Its spatial resolution $(\sim 60 \mathrm{~km}, \sim 50 \%$ lower than the SMAP and SMOS resolutions) would limit a number of applications over land, but it would be extremely useful over the ocean [18]. Aperture synthesis radiometers such as the L/S/C-band radiometer of WCOM (Water Cycle Observation Mission) [16] or SMOS-HR (SMOS-High Resolution), currently in Phase 0 at CNES [11], with a target resolution of $\sim 10 \mathrm{~km}$, would ensure the continuity of passive L-band observations at better resolution than provided by current satellites for soil moisture studies and other land applications. We are confident that all those exciting future missions will result in a wealth of scientific discovery and many more Remote Sensing Special Issues in the future. For the time being, we hope that Remote Sensing readers will enjoy the current Special Issue as much as we have enjoyed our role as academic guest editors.

Acknowledgments: We thank the Remote Sensing Editorial Office staff (in particular Nelson Peng) and the "Remote Sensing in Geology, Geomorphology and Hydrology" Section Editor-in-Chief (Richard Gloaguen) for their support and help with the editorial work of this Special Issue. A partial contribution to this effort was made at the Jet Propulsion Laboratory, California Institute of Technology under contract with National Aeronautics and Space Administration.

\section{References}

1. Cui, C.; Xu, J.; Zeng, J.; Chen, K.S.; Bai, X.; Lu, H.; Chen, Q.; Zhao, T. Soil moisture mapping from satellites: An intercomparison of SMAP, SMOS, FY3B, AMSR2, and ESA CCI over two dense network regions at different spatial scales. Remote Sens. 2018, 10, 33. [CrossRef]

2. Li, C.; Lu, H.; Yang, K.; Han, M.; Wright, J.S.; Chen, Y.; Yu, L.; Xu, S.; Huang, X.; Gong, W. The Evaluation of SMAP Enhanced Soil Moisture Products Using High-Resolution Model Simulations and In-Situ Observations on the Tibetan Plateau. Remote Sens. 2018, 10, 535. [CrossRef]

3. El Hajj, M.; Baghdadi, N.; Zribi, M.; Rodríguez-Fernández, N.; Wigneron, J.P.; Al-Yaari, A.; Al Bitar, A.; Albergel, C.; Calvet, J.C. Evaluation of SMOS, SMAP, ASCAT and Sentinel-1 Soil Moisture Products at Sites in Southwestern France. Remote Sens. 2018, 10, 569. [CrossRef]

4. Wagner, W.; Jackson, T.J.; Qu, J.; de Jeu, R.; Rodriguez-Fernandez, N.; Reichle, R.; Brocca, L.; Dorigo, W. 4th Satellite Soil Moisture Validation and Application Workshop. Glob. Energy Water Exchang. Newsl. 2017, $28,13-14$.

5. Souza, A.; Neto, A.; Rossato, L.; Alvalá, R.; Souza, L. Use of SMOS L3 Soil Moisture Data: Validation and Drought Assessment for Pernambuco State, Northeast Brazil. Remote Sens. 2018, 10, 1314. [CrossRef]

6. Paredes-Trejo, F.; Barbosa, H.; Rossato Spatafora, L. Assessment of SM2RAIN-Derived and State-of-the-Art Satellite Rainfall Products over Northeastern Brazil. Remote Sens. 2018, 10, 1093. [CrossRef]

7. Small, E.E.; Badger, A.M.; Abolafia-Rosenzweig, R.; Livneh, B. Estimating Soil Evaporation Using Drying Rates Determined from Satellite-Based Soil Moisture Records. Remote Sens. 2018, 10, 1945. [CrossRef]

8. Han, M.; Zhu, Y.; Yang, D.; Hong, X.; Song, S. A Semi-Empirical SNR Model for Soil Moisture Retrieval Using GNSS SNR Data. Remote Sens. 2018, 10, 280. [CrossRef]

9. Schwank, M.; Naderpour, R.; Mätzler, C. "Tau-Omega"-and Two-Stream Emission Models Used for Passive L-Band Retrievals: Application to Close-Range Measurements over a Forest. Remote Sens. 2018, 10, 1868. [CrossRef] 
10. Meyer, T.; Weihermüller, L.; Vereecken, H.; Jonard, F. Vegetation Optical Depth and Soil Moisture Retrieved from L-Band Radiometry over the Growth Cycle of a Winter Wheat. Remote Sens. 2018, 10, 1637. [CrossRef]

11. Rodriguez-Fernandez, N.; Anterrieu, E.; Rougé, B.; Boutin, J.; Picard, G.; Pellarin, T.; Escorihuela, M.; Cabot, F.; Richaume, P.; Khazaal, A.; et al. SMOS-HR: A high resolution L-band passive radiometer for Earth science and applications. IGARSS 2019, submitted.

12. Xu, H.; Yuan, Q.; Li, T.; Shen, H.; Zhang, L.; Jiang, H. Quality Improvement of Satellite Soil Moisture Products by Fusing with In-Situ Measurements and GNSS-R Estimates in the Western Continental US. Remote Sens. 2018, 10, 1351. [CrossRef]

13. Lorenz, C.; Montzka, C.; Jagdhuber, T.; Laux, P.; Kunstmann, H. Long-Term and High-Resolution Global Time Series of Brightness Temperature from Copula-Based Fusion of SMAP Enhanced and SMOS Data. Remote Sens. 2018, 10, 1842. [CrossRef]

14. Cenci, L.; Pulvirenti, L.; Boni, G.; Pierdicca, N. Defining a Trade-off Between Spatial and Temporal Resolution of a Geosynchronous SAR Mission for Soil Moisture Monitoring. Remote Sens. 2018, 10, 1950. [CrossRef]

15. Wu, M.; Scholze, M.; Kaminski, T.; Vossbeck, M.; Georg, H. Constraining terrestrial carbon and water fluxes using remotely sensed SMOS soil moisture and FAPAR data at multiple sites within the Carbon Cycle Data Assimilation System. Remote Sens. 2018, 10, 569.

16. Shi, J.; Zhao, T.; Cui, Q.; Yao, P. Airborne and Spaceborne Passive Microwave Measurements of Soil Moisture. In Observation and Measurement of Ecohydrological Processes; Li, X., Vereecken, H., Eds.; Springer: Berlin/Heidelberg, Germany, 2018; pp. 1-35.

17. Kerr, Y.; Rodriguez-Fernandez, N.; Entekhabi, D.; Bindlish, R.; Lee, T.; Yueh, S.; Lagerloef, G.; Wigneron, J.P.; Boutin, J.; Reut, N.; et al. Present and Future of L-Band Radiometry. In Proceedings of the 2018 IEEE International Geoscience and Remote Sensing Symposium, Valencia, Spain, 22-27 July 2018; pp. 1994-1997.

18. Kilic, L.; Prigent, C.; Aires, F.; Boutin, J.; Heygster, G.; Tonboe, R.T.; Roquet, H.; Jimenez, C.; Donlon, C. Expected Performances of the Copernicus Imaging Microwave Radiometer (CIMR) for an All-Weather and High Spatial Resolution Estimation of Ocean and Sea Ice Parameters. J. Geophys. Res. Oceans 2018, 123, 7564-7580. [CrossRef]

(C) 2019 by the authors. Licensee MDPI, Basel, Switzerland. This article is an open access article distributed under the terms and conditions of the Creative Commons Attribution (CC BY) license (http://creativecommons.org/licenses/by/4.0/). 